DOI: $10.1515 / a a-2017-0007$

\title{
Full Access to Cultural Spaces (FACS): Mapping and evaluating museum access services using mobile eye-tracking technology
}

Francesca Raffi

Francesca Raffi holds a $\mathrm{PhD}$ in audiovisual translation and is currently lecturer in English language and translation at the University of Macerata, Italy. She was a research team member of the Full Access to Cultural Spaces (FACS) project at the University of Macerata, and she is currently a member of the INRESET (Interdisciplinary Research with Eye-Tracking Technology) research team (University of Macerata). Her main research interests include audiovisual translation (mainly from a diachronic and historical perspective) and accessibility to media, arts and culture.

\begin{abstract}
The present paper aims to present significant results stemming from the FACS (Full Access to Cultural Spaces) project, launched in 2014 by the University of Macerata and concluded in 2016. In particular, this paper reports on stages one and two of the FACS project which aimed first to explore the state of the art of universal access services across a large variety of museums in Italy and nine other EU countries. Based on the first stage, an analysis of some of the most significant data obtained from a questionnaire sent out to over 1,200 European museums will be presented, with a special focus on multilingual devices and access services for the sensory impaired. The first stage was followed by an eye-tracking study on an Italian museum, Turin's Museo Nazionale del Cinema (National Cinema Museum), aimed at evaluating visitors' experience, attitudes and patterns of fruition through a test with a portable eye tracker (Tobii Pro Glasses 2, $50 \mathrm{~Hz}$ ). Based on this second stage, the fruition of information panels by museum visitors at the Museo Nazionale del Cinema will be explored, specifically focusing on reading patterns and behaviours.
\end{abstract}

\section{Introduction}

The number of museums around the world has increased from 22,000 in 1975 to 55,000 today (UNESCO 2017). ${ }^{1}$ While physical accessibility to cultural heritage is a paramount concern, there is an increased awareness that museums carry not only an educational responsibility but also an ethical one to create spaces geared towards the needs of all audiences, thus overcoming social exclusion and promoting universally accessible culture.

Several guidelines and protocols have been issued to guide museums in achieving the goal of 
universal accessibility, such as Article 30 of the United Nations' Convention on the Rights of Persons with Disabilities (2007). Moreover, a number of organizations and institutions have led the field in raising awareness of this challenge and suggesting best practices at both European and international levels. As such, a number of museums were asked to meet the needs of their visitors (Komarac, 2014) and improve visitor experiences (Kawashima, 1999).

In light of the above, the present paper aims to present some significant results stemming from the FACS (Full Access to Cultural Spaces) project, launched in 2014 by the University of Macerata and concluded in 2016. Originating out of collaboration among researchers in audiovisual translation, psychology, museology, IT and usability, ${ }^{2}$ the project aimed first to explore the state of the art of universal access services across a large variety of museums in Italy and nine other EU countries. This first stage was then followed by an eye-tracking study on an Italian museum, Turin's Museo Nazionale del Cinema (National Cinema Museum), aimed at evaluating visitors' experience, attitudes and patterns of fruition through a test with a portable eye tracker (Tobii Pro Glasses 2, $50 \mathrm{~Hz}$ ), and a brief final survey. Finally, the analyses stemming from the first stage and the data from the eye-tracking test were joined, in an attempt to draw up a comprehensive model for universal accessibility to museums and cultural spaces, to be tested on more museums across Europe.

In particular, this paper reports on stages one and two of the FACS project. Based on the first stage, an analysis of some of the most significant data obtained from a questionnaire sent out to over 1,200 European museums will be presented, with a special focus on multilingual devices and access services for the sensory impaired. An overview of the access services available in museums for each country as well as for the whole sample will also be provided.

Based on the second stage, the fruition of information panels by museum visitors at the Museo Nazionale del Cinema will be explored, focusing on reading patterns and behaviours.

Before moving on to the studies conducted in phases one and two, in the following section the concept of accessibility that the FACS project embraces, in line with the principles of universal design, will be discussed, together with the motivations for the integration of mobile eye-tracking (MET) technology.

\section{Accessibility for all and the FACS project}


Defining accessibility is an ongoing and constantly changing process, both across time and societies (Ryhl, 2009). In the past, the accessibility framework focused on physiology (Ryhl, 2016, p. 118) and was mainly intended as the removal of architectural or sensory barriers to ensure equal access to persons with physical or sensory impairments.

Today, most societies feel the impact of demographic, economic, social and technological transformations which are in turn shaping our local, national and international communities. Population ageing, global migration and rapid technological advances, to name but a few, are broadening the concept and definition of disability to also include all age-related, technological, cultural, social and language-related issues.

Therefore, the term accessibility can now be defined as the degree to which a product, a service device or environment is available to everyone, to the greatest extent possible, including (but not exclusively) people with physical, sensory or cognitive disabilities. Therefore, this new definition suggests that the concept of accessibility should be intended in its broadest sense, and combined with those of inclusion (i.e. participation) and universality (i.e. equality).

In line with the universal design principles, that is "a process that enables and empowers a diverse population by improving human performance, health and wellness, and social participation" (Steinfeld, Maisel, 2012), the expression universal accessibility has been coined to describe "the nature of a product, process, service, environment or means of access to information which, in an inclusive view, allows all users, including those that may have (or experience) limitations, to obtain by themselves equivalent results in activities" (Rocque et al., 2015, p. 175).

As a consequence, the old homogeneous concept of accessibility, which only addressed the needs of certain categories of the population with some kind of physical, sensory or cognitive impairment, has evolved into a more heterogeneous concept which has been embraced by scholars theorizing on how the right to accessibility should be intended today (Greco, 2016). In this sense, the field of media accessibility has proven to be very fruitful, emphasizing and further expanding in many directions the question of accessibility for all (Díaz Cintas, 2005; Díaz Cintas, Orero, Remael, 2007, pp. 11-20; Mangiron, Orero, O’Hagan, 2014, among others).

As for the field of cultural heritage, Davidson, Heald and Hein (1991) focused on the need for and benefits of extending accessibility to the entire museum public at the Boston Museum of Science, in order to make both the environment and the content more available to all visitors, 
including (but not exclusively) to those with disabilities. Ang (2005) made a further step towards the omni-comprehensive concept of museum accessibility, trying to overcome class and cultural hierarchies at the Art Gallery of New South Wales (Sydney) and to engage cultural diversity in the art museum.

As for technological tools applied to museum accessibility, Ruiz et al. (2010) adopt a Multimedia Guides for All approach to facilitate universal access to museums via multimedia and portable guides, making access available to all, independent of their sensory disabilities or technological competency. Along the same lines, Hurtado et al. (2012) propose the development of a multimedia guide prototype for Granada's Parque de las Ciencias (Science Park Museum) based on a combination of translation and interpreting modalities to improve museum accessibility for all. Álvarez de Morales Mercado and Hurtado (2016) strengthen the interrelation between translation and accessibility while Sørmoen, Arenghi and Garofalo (2016) further develop the issues related to participation by everyone in the enjoyment of cultural heritage, conceiving accessibility as a key strategy for building a truly inclusive society.

Therefore, in keeping with the principles of universal design and following the path traced by the above-mentioned contributions, in 2014 the University of Macerata (Italy) launched a twoyear project, FACS (Full Access to Cultural Spaces). The aim was to address the question of accessibility to museums and exhibitions focusing on all variables in the provision of appropriate, innovative access services: from the technologies used to their effective usability, from the texts designed for access to their appropriate reception by diverse categories of the population.

The project, founded on a full integration of competences, knowledge, and experiences, comprised two different but interrelated steps. First, practices and experiences of 128 museums in Italy and 9 other EU countries were examined in order to map the state of the art in the field of museum access services, at the time the FACS project was launched.

Bringing together the results from the previous stage, in 2015-2016 an important Italian museum, the Museo Nazionale del Cinema (National Cinema Museum, Turin), which agreed to support the project throughout and collaborated as an active case study, was explored in order to study the museum visit experience, evaluate the accessibility services provided, as well as their possible simplification and standardization.

Even though many studies have been conducted over the years to understand the whole visitor and visit experience in cultural heritage settings (Falk, 2009), little research has been done to 
monitor, analyse and use eye gaze for inferring user interests in mobile scenarios (Mokatren, Kuflik, 2016). This is the case of the cultural heritage domain, which forces users to split their attention between several tasks at the same time: gathering information, paying attention to objects exhibited, interacting with available tools, accessing the services provided, among other things.

In light of the above, mobile eye-tracking (MET) technology was integrated into the second phase of our project in order to monitor and analyse users' visit experience at the Museo Nazionale del Cinema, thus trying to investigate the correlations between the observed patterns, meanings and the goals of attention (Holmqvist et al., 2011) to possibly draft a comprehensive model for a strong, integrated and universal museum accessibility.

Finally, data derived from step one and step two was combined in order to draft a comprehensive, integrated model for true, technologically based, easy-to-use accessibility for museums, to be perfected and possibly further developed through larger-scale studies.

In the following sections, the first and second phase of our project will be presented and some of the major results achieved will be discussed, thus offering a tentative picture of the main access services available in Europe (see Section 3) and of how these resources are actually accessed by museum visitors (see Section 4).

\section{The FACS Project: Mapping museum access services in Europe (Stage One)}

Following the categorization proposed by Hurtado (2012), museum accessibility can be divided into two main areas: accessibility to the museum's physical environment; and accessibility to the museum's contents. The first step of the FACS project focused on the latter, namely accessibility resources that museums provide to visitors, thus adapting their contents to different types of users.

If inclusion and universal design constitute the main reference framework for this project (see Section 2), its pioneering nature made it possible to focus mainly on access services for certain categories of the population. Therefore, besides the traditional portable guides and information

panels for different languages, it will evaluate the effective implementation by European museums of more contemporary tools such as tagging systems for mobile phones, tabletsupported multifunctional guides, specific materials for the visually, hearing, and cognitive 
impaired as well as access services designed for children.

\subsection{Study design}

According to the Abridged List of Key Museum Indicators (EGMUS, 2012), we can count around 20,000 medium and large museums in Europe. As a consequence, considering that the size of the population was too large to attempt to survey all of its members, we randomly selected 125 museums in 10 European countries (Italy, Spain, France, Germany, Poland, Greece, Portugal, Sweden, Belgium and the UK). Therefore, our results and preliminary conclusions do not intend to make any generalizations. Still, we can provide a rich and detailed picture of some trends which could be detected at the European level, as far as our sample is concerned.

We invited participants to answer a questionnaire composed of 34 questions, divided into seven different groups: demographics information; multilingual access services; access for the visually impaired; access for the hearing impaired; access for people with cognitive impairment; access for children/young; and future projects (i.e. access services to be implemented in the near future).

From March to December 2014, we sent more than 1,200 questionnaires using Lime Survey (2003), a free and open source online survey application, together with a cover letter presenting the study and providing simple instructions, available in four languages (Italian, English, French and Spanish).

In the following sections, the key findings for each of the access service sections will be discussed. In particular, we will focus on multilingual access services, access services for the visually impaired, and access services for the hearing impaired.

For each category, participants were provided with a close-ended question listing all options available, from which they could choose all that applied; if no options applied, participants could freely add further options. Interestingly enough, this resulted in being particularly useful for the visually impaired and hearing impaired groups of questions, as will be shown in the following sections.

\subsection{Key findings}


We received 128 answers from all the selected countries, and more precisely: 29\% Italy; 23\% Greece; 18\% Spain; 13\% Poland; 12\% Sweden; 11\% Portugal; 10\% Germany; 9\% France and UK, respectively; and 5\% Belgium.

It was agreed that the sample should be heterogeneous with regard to museum types in order to provide a picture which was as comprehensive as possible. As for the predominant collections, among the more than 40 different museum typologies gathered, archaeological (15\%), history (10\%), science/technology (11\%), and military/war museums $(7 \%)$ are the most represented (see Table 1).

\begin{tabular}{|c|c|c|c|}
\hline \multicolumn{4}{|c|}{ What type of museum is yours? } \\
\hline & $\%$ & & $\%$ \\
\hline Ancient Art museum/Gallery & 7 & History museum & 10 \\
\hline Archaeological museum & 15 & Industry museum & 1 \\
\hline Astronomy museum & 0 & Literary museum & 1 \\
\hline Cinema museum & 1 & Military/War museum & 7 \\
\hline City museum & 3 & Modern Art museum/Gallery & 5 \\
\hline Contemporary Art museum/Gallery & 4 & Music/Musical instruments museum & 1 \\
\hline Costumes/Fashion museum & 0 & Natural History museum & 3 \\
\hline Ethnographic museum & 3 & Performing Arts museum & 1 \\
\hline Folk museum & 2 & Photography museum/Gallery & 0 \\
\hline Toy museum & 1 & Planetarium & 0 \\
\hline Historic house museum & 4 & Transport museum & 1 \\
\hline Theatre/Opera museum & 1 & Virtual museum & 0 \\
\hline Science/Technology museum & 11 & Wax museum & 0 \\
\hline
\end{tabular}

\section{Table 1 Museum typologies}

In terms of size, our sample included small, medium and large sized museums, with different numbers of visitors during the 2012-2014 two-year period, as well as museums based in both well-known cultural districts and in smaller geographical areas: from Casa Leopardi located in Recanati, a small village in the Marche region, to the Picasso Museum in Barcelona; from the Übersee-Museum Bremen to London's British Museum.

As for the section "Multilingual Access", we asked what kind of service(s) museums were offering their visitors. As shown in Table 2 below, almost $80 \%$ of museums reported that printed materials still represented the major resources provided (print guides/brochures/leaflets), 
followed by panels and posters $(53 \%)$.

\begin{tabular}{|c|c|c|}
\hline$\#$ & What multilingual access service(s) does your museum offer to its visitors? & $\%$ \\
\hline $\mathbf{1}$ & Print guides/brochures/leaflets & 78 \\
\hline $\mathbf{2}$ & Panels/posters & 53 \\
\hline $\mathbf{3}$ & Portable audio guides & 33 \\
\hline $\mathbf{4}$ & Downloadable guides for use on smartphones and/or tablets & 13 \\
\hline $\mathbf{5}$ & Tagging systems & 8 \\
\hline $\mathbf{6}$ & Guides available on tablets & 7 \\
\hline $\mathbf{7}$ & Google glasses or similar & 0 \\
\hline
\end{tabular}

Table 2 Multilingual access service(s) for our European sample

Along with the more traditional portable audio guides (33\%), it seemed that technologically advanced solutions were timidly gaining ground, with downloadable guides for use on smartphones and/or tablets (13\%), tagging systems (8\%), and finally guides available on tablets $(7 \%)$.

As shown in Table 3 below, while print materials were the preferred solution for all countries included in our study, with the highest percentages in France and Belgium, where all museums selected this option, the majority of European museums seemed to be reluctant to provide multilingual access services through technological devices.

\begin{tabular}{|c|c|c|c|c|c|c|c|c|c|c|}
\hline & BEL & FRA & GER & GRE & ITA & POL & POR & SPA & SWE & UK \\
\hline Print guides/brochures/leaflets & 100 & 100 & 70 & 73 & 83 & 92 & 75 & 62 & 67 & 75 \\
\hline Panels/posters & 71 & 40 & 30 & 72 & 79 & 31 & 33 & 31 & 58 & 0 \\
\hline Portable audio guides & 29 & 20 & 50 & 36 & 38 & 46 & 17 & 31 & 17 & 0 \\
\hline $\begin{array}{c}\text { Downloadable guides for use } \\
\text { on smartphones and/or tablets }\end{array}$ & 43 & 40 & 0 & 18 & 8 & 0 & 0 & 23 & 17 & 0 \\
\hline Guides available on tablets & 0 & 40 & 10 & 5 & 0 & 0 & 0 & 8 & 25 & 0 \\
\hline Tagging systems & 0 & 20 & 10 & 9 & 4 & 15 & 0 & 15 & 8 & 0 \\
\hline Google glasses or similar & 0 & 0 & 0 & 0 & 0 & 0 & 0 & 0 & 0 & 0 \\
\hline
\end{tabular}

Table 3 Multilingual access service(s) for each European country

As far as technology is concerned, significant percentages were observed only in France, which seemed to provide a larger and more varied range of technologically advanced services. Finally, Google glasses or similar tools seemed to be completely ignored by European museums. 
Interestingly enough, moving to access services offered for the visually impaired, as shown in Table 4 below, the majority of museums did not find in any of the solutions provided a valid option $(41 \%)$.

\begin{tabular}{|c|c|c|}
\hline \# & What access service(s) for the visually impaired does your museum offer to its visitors? & $\%$ \\
\hline 1 & None of the above & 41 \\
\hline 2 & Tactile material & 23 \\
\hline 3 & Large print on guides/brochures/leaflets and/or panels/posters & 18 \\
\hline 4 & Audio descriptions & 15 \\
\hline 5 & Portable audio guides & 15 \\
\hline 6 & Braille on panels/posters & 9 \\
\hline 7 & Braille portable guides & 7 \\
\hline 8 & Downloadable audio guides for use on smartphones and/or tablets & 4 \\
\hline 9 & Magnification equipment & $3 \%$ \\
\hline 10 & Guided tours on tablets & $2 \%$ \\
\hline
\end{tabular}

Table 4 Access service(s) for the visually impaired for our European sample

Consequently, they autonomously indicated further alternatives, and it was found that specific sessions led the way, with "workshops" as the most frequent option provided (15\%), which clearly falls out of universal design and the "for all" inclusive policies.

However, as shown in Table 4 above, printed resources seemed to occupy again a primary position in the range of museum access services, in particular tactile materials (23\%) and large print on guides/brochures/leaflets and/or panels/posters (18\%). Quite unpredictably, audio resources did not record significant percentages, with portable audio guides and audio descriptions accounting for less than $20 \%$ of all available options. As for more technologically advanced services, downloadable audio guides for use on smartphones and/or tablets and guided tours on tablets only accounted for less than 5\%.

As shown in Table 5 below, print materials were the preferred access services offered by the majority of European museums participating in the study.

\begin{tabular}{|c|c|c|c|c|c|c|c|c|c|c|}
\hline & BEL & FRA & GER & GRE & ITA & POL & POR & SPA & SWE & UK \\
\hline Portable audio guides & 50 & 33 & 0 & 17 & 24 & 0 & 25 & 11 & 9 & 0 \\
\hline $\begin{array}{l}\text { Downloadable audio guides for } \\
\text { use on smartphones and/or } \\
\text { tablets }\end{array}$ & 0 & 17 & 0 & 4 & 0 & 10 & 0 & 11 & 0 & 13 \\
\hline
\end{tabular}




\begin{tabular}{|c|c|c|c|c|c|c|c|c|c|c|}
\hline Guided tours on tablets & 0 & 0 & 13 & 0 & 0 & 0 & 0 & 0 & 0 & 13 \\
\hline Audio descriptions & 0 & 17 & 0 & 4 & 14 & 20 & 13 & 22 & 27 & 38 \\
\hline Braille portable guides & 0 & 0 & 13 & 0 & 10 & 10 & 13 & 0 & 18 & 13 \\
\hline Braille on panels/posters & 0 & 17 & 0 & 4 & 10 & 30 & 25 & 6 & 9 & 0 \\
\hline Tactile material & 0 & 33 & 25 & 13 & 19 & 40 & 38 & 22 & 27 & 25 \\
\hline $\begin{array}{c}\text { Large print on } \\
\text { guides/brochures/leaflets } \\
\text { and/or panels/posters }\end{array}$ & 0 & 17 & 13 & 22 & 19 & 30 & 25 & 11 & 27 & 0 \\
\hline \begin{tabular}{c} 
Magnification equipment \\
\hline
\end{tabular} & 25 & 0 & 0 & 4 & 0 & 10 & 0 & 0 & 9 & 0 \\
\hline
\end{tabular}

\section{Table 5 Access service(s) for the visually impaired for each European country}

Despite the success of print materials, large print on guides/brochures/leaflets and/or panels/posters seemed to be totally absent from museums in Belgium and in the UK which, on the other hand, seemed to largely rely on tactile materials (25\%). However, audio descriptions were the preferred option selected by British museums (38\%), which is also the country which relied more heavily on audio description than any other European country.

Similar to what happened for the previous section, European museums participating in the study did not select any of the options provided among the services for the hearing impaired listed in the questionnaire (see Table 6 below). Once again, guided tours, workshops, activities and special projects were the most frequent options added by respondents, thus confirming the tendency to create special and temporary opportunities of inclusion instead of a permanent inclusive environment for everyone.

\begin{tabular}{|c|c|c|}
\hline$\#$ & What access service(s) for the hearing impaired does your museum offer to its visitors? & \% \\
\hline $\mathbf{1}$ & None of the above & 67 \\
\hline $\mathbf{2}$ & Live subtitles/captions on screens & 6 \\
\hline $\mathbf{3}$ & Pre-recorded subtitles/captions on screens & 6 \\
\hline $\mathbf{4}$ & Live sign language interpretation & 3 \\
\hline $\mathbf{5}$ & Downloadable subtitles for use on smartphones and/or tablets & 3 \\
\hline $\mathbf{6}$ & Guided tours on tablets & 2 \\
\hline $\mathbf{7}$ & Pre-recorded sign language interpretation on screens & 6 \\
\hline
\end{tabular}

\section{Table 6 Access service(s) for the hearing impaired for our European sample}

Subtitling seemed to lead the way, with live subtitles/captions on screens and pre-recorded subtitles/captions on screens as the preferred option, together with live sign-language interpretation (6\%). As far as technology is concerned, only 3\% of all European museums 
seemed to provide hearing impaired visitors with downloadable subtitles for use on smartphones and/or tablets and guided tours on tablets. Interestingly enough, the implementation of new technological tools seems to play a major role in the future agenda of all European museums.

In the last section of the questionnaire, we asked through two related open-ended questions what new or additional services museums were planning to develop in the following three-year period (2015-2018), and for what kind of visitors. As for the former, we grouped the received answers according to six macro-categories, as shown in Table 7 below.

\begin{tabular}{|c|c|c|}
\hline$\#$ & What new or additional services your museum is planning to include in the next three years & \% \\
\hline 1 & Smartphone/tablet technology & 35.4 \\
\hline 2 & Audio guides & 30.9 \\
\hline 3 & Multimedia technology & 23.6 \\
\hline 4 & Tactile material & 14.5 \\
\hline 5 & Braille & 7.2 \\
\hline 6 & Website/online sources/social media & 9 \\
\hline 7 & Print material & 9 \\
\hline 8 & Nothing & 3.6 \\
\hline 9 & Audio description & 3.6 \\
\hline 10 & Tagging system & 1.8 \\
\hline
\end{tabular}

\section{Table 7 Additional services for the future}

Despite the fact that until 2014 advanced technology seemed to have been disregarded by European museums, the implementation of smartphone/tablet technology was listed as the top priority for providing future access services to visitors.

As for the target visitors to which these additional services would be addressed, we find: $30 \%$ visually impaired; 20\% hearing impaired and foreigners, respectively; 9\% children/young; 4\% disabled (without any reference to the kind of disability); and $2 \%$ elderly.

The above-discussed results date back to 2014 and we are not able to say if the situation has changed since then, as far as our sample of 10 European countries is concerned. However, the picture that can be drawn is quite clear, even when taking into account the above-mentioned limitations.

If the concept of accessibility is widespread and present in every modern society, the results achieved show that museums have not implemented it in their practice in either a developed or committed way. Despite the fact that museums play a clear role as disseminators of all types of 
knowledge, our analysis of the situation of European museums also shows that the percentage of museums having adopted comprehensive and successful accessibility plans in line with the principles of universal design is very low.

This is hardly surprising if we consider that comprehensive accessibility plans entail significant financial investment, as well as a great deal of work by various professionals from different fields of expertise. In fact, from the data collected, it is clear that paper materials, being less expensive, were still the preferred access services provided.

Therefore, starting from this result, in the following section we will investigate how museum visitors interact with these materials, thus exploring visitors' reading patterns and behaviours.

\section{The FACS Project: Mapping museum experience at Turin's Museo del Cinema (Stage Two)}

The second stage of the FACS project aimed to evaluate users' attitudes and patterns of fruition at an Italian museum which collaborated as an active case study, Turin's Museo Nazionale del Cinema (National Cinema Museum). This museum was selected not only for its importance at national and international level but also because its main aim is to provide visitors with different stimuli, so as to reproduce the experience of being in a cinema and watching a film. Consequently, the museum provides visitors with all the typologies of access services which have already been mapped in Section 3, from multilingual to tactile materials, from text panels to audio guides, thus perfectly representing the concept of accessibility that this project has embraced.

We focused on a permanent collection of the museum, specifically, the "Archaeology of Cinema", which is composed of eight sections. These sections are thematically arranged to guide visitors through the history of cinema and offer rare collections which also narrate the development of new technologies and new cinematic techniques. For a more accurate evaluation of the visitor experience, we concentrated on only four of these areas: Optics, Peepshows, Stereoscopy and Panorama. These four areas are positioned in sequence, one following the other, on the right side of the exhibition room. The first one "Optics", traces the history of optical science, which boomed in the field of cinema in the 17th century. The second one is dedicated to "Peepshows", also called perspective boxes in the UK, an optical device which used lenses and 
candles to magnify images. The third one "Stereoscopy", is dedicated to the stereoscope, which was invented in the 19th century to create two-dimensional images. The last one "Panorama", offers a wide-angle view or representation of a physical space or landscape exhibited inside a circular building, and dating back to the 18th century. While Optics, Peepshows, Stereoscopy and Panorama are placed on the right of the room, on the left there are a few recesses with (mostly interactive) objects related to some of the showcases.

Each section includes a showcase with the objects exhibited and distributed on two different shelves, one above the other; an information panel including one or two Italian texts divided into different columns, along with their respective English translations; an interactive screen; and a red non-interactive screen called "highlight". Since the main intention of the museum was to make this collection as accessible as possible to everyone, a highlighted path (or simply highlights) was introduced for those visitors who do not have enough time to enjoy a full visit but who, at the same time, do not want to miss the most important and representative objects exhibited in the showcases.

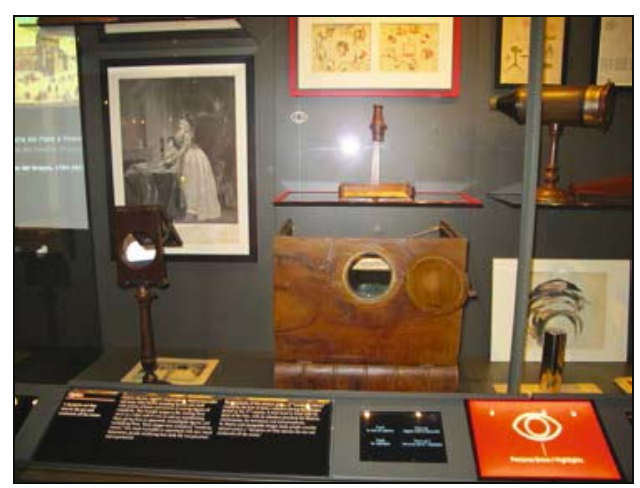

Figure 1 Highlight path: red screen and highlighted objects in the showcase

As shown in Figure 1 above, the highlighted path is signalled by the red screen, which is intended to direct visitors' attention towards the objects highlighted in red and exhibited in the showcases.

In our study, we discovered that only $12.5 \%$ of visitors actually looked at the red screen. Even more interestingly, when they looked at the red screen, they did not follow the red line, so they did not in fact look at the objects outlined in red. We also detected that they mostly interacted with the red screen in the "wrong" way: they initially thought it was an interactive screen, only to be disappointed to learn that it was not, so they simply left it or ignored it completely.

In the present paper, we will focus on the information panel of each section in order to investigate how visitors interact with these materials and to try to evaluate visitors' experience. 
Therefore, we monitored eye gaze through Tobii Pro Glasses 2, a new generation eye tracker which enables researchers to infer user interests in mobile scenarios.

\subsection{Study design}

Even if Tobii Pro Glasses 2 enable researchers to analyse a dynamic environment, for quantitative analysis to be meaningful the collected eye-tracking data needs to be analysed using fixed objects. Therefore, we first took 42 photos using a digital camera. These would be used as snapshots, i.e. still images of objects of interest in the environment under scrutiny.

Bearing our objective in mind, we divided the snapshots into three groups, according to the objects included: showcases with objects exhibited; showcases, information panels and interactive/information screens; information panels and interactive/informative screens. Snapshots were then imported into a computer running analysis software to be later used for the qualitative and quantitative analysis of the collected data.

We then selected our sample of visitors randomly, only excluding those with corrective vision devices such as glasses and contact lenses. After providing visitors with all the necessary information that would help them in deciding whether or not they wished to take part in the experiment, participants were asked to wear the Tobii Pro Glasses $(50 \mathrm{~Hz})$ and to simply visit the four sections freely, without any further instruction.

Finally, visitors were asked to complete a questionnaire at the end of the visit in order to collect personal information and to establish whether previous experiences in the same or similar museums could have influenced their visit. Data from the questionnaire were then qualitatively elaborated both to be implemented in our analysis and to more precisely define our sample (age, occupation, nationality, previous visits to the museum, etc.).

We collected a total of 20 participants but only 16 provided usable video recordings for the analysis. This was because we had some losses in terms of precision, during extreme eye movements, in cases where the head unit moved slightly on the wearer, or in cases where the participant moved in areas which were too far from the recording unit. Since this could somehow negatively impact on the data analysis and final results, we decided to include only those recordings which provided at least $85 \%$ of valid data, reaching a fairly high $88 \%$ on average.

Our final sample was composed of 9 men and 7 women, with ages ranging from 18 to 60 years 
old, so a broad sample in terms of age.

\subsection{Key findings}

As for the first section, "Optics", 6.6\% participants ignored the area under scrutiny, and the average visit duration was one minute and 13 seconds.

Considering the total visit duration, ${ }^{3}$ visitors dedicated more than $80 \%$ of their time interacting with the informative area (i.e. information panel and interactive screen), and less than $20 \%$ looking at the objects exhibited. In terms of fixation duration, ${ }^{4}$ around $85 \%$ is concentrated on the informative tools, and less than $15 \%$ on the objects exhibited. Interestingly enough, despite the interactive and more dynamic nature of the informative screen, it is the information panel, comprising only an Italian text together with its English translation, which attracted visitors' attention the most: $67 \%$ against $32 \%$, in terms of fixation duration.

As far as the information panel is concerned, the English text was only quickly scanned for less than 200-250 milliseconds by all visitors, thus resulting in no fixations.

As for the Italian text, it is made up of 20 lines and divided into two columns. A detailed analysis of the way participants read its content shows that users devoted most of the time (total fixation duration) to the first column, which averaged $34 \%$, while the second column and the title totalled $17 \%$, respectively.

The first column contains expressions such as "anamorfosi catottriche" (catoptric anamorphosis) and "paradossi diottrici" (dioptrical paradoxes). All four words are absent from Nuovo Vocabolario di Base della Lingua Italiana De Mauro (2016), which integrates high frequency vocabulary ranges, thus describing the most used and understood words of the Italian language. In addition to that, Dizionario della Lingua Italiana De Mauro (2017, online) labels all the above-mentioned terms as technical-specific ones, not belonging to the general language but to jargon. Consequently, they are all rather complex to process for the average audience, and this is likely to be the reason for the high percentage of fixations on that portion of text.

Interestingly enough, $30 \%$ of readers started directly from the second column, thus shortening their reading effort by skipping both the title and the first column altogether. In particular, $24 \%$ of the time was spent on the first four lines and around 5\% on the remaining text. Again, in the first part of the second column we find a complex sentence "la galassia proteiforme delle mirabili visioni $[\ldots]$ " (The protean galaxy of wondrous visions $[\ldots]$ ), whose terms are again absent from 
Nuovo Vocabolario di Base della Lingua Italiana De Mauro (2016).

Moving to the second section, "Peepshows", this section ranked first in terms of time spent visiting it, with an average visit duration of one minute and 37 seconds. However, 13.3\% visitors ignored it. After carefully examining all video recordings, we can say that the smaller number of visitors is maybe due to the fact that in front of this section participants found a mostly entertaining area called "Phantasmagoria", with various interactive tools which reproduced the experience of this form of horror theatre.

Going back to the area under scrutiny, considering the total visit duration, visitors dedicated more than $65 \%$ of their time interacting with the information panel and $32 \%$ with the interactive screen. The objects exhibited were only quickly scanned for less than 200-250 milliseconds, thus resulting in no fixations.

As far as the information panel is concerned, once again no fixation was detected on the English version. As for the Italian section, which comprises two different texts of nearly 30 lines each, visitors focused mostly on the title of the first text and, interestingly enough, on the first column of the second text, entitled "Scatole ottiche per diorami teatrali".

Participants reached this area after visiting the previous section, "Optics", to the right. Consequently, the first text in front of them is the second text of the information panel, and this may explain the higher proportion of fixation for the second text. More specifically, participants spent almost $64 \%$ of the time on the first section (title and first paragraph), $23 \%$ on the following paragraph, and $12 \%$ on the last one.

Moving to the third section, "Stereoscopy", all participants visited this section, ranking second in terms of time spent visiting it (one minute and 34 seconds). In particular, participants spent $57 \%$ of the overall time on the informative area (information panel and interactive screen) and less than $20 \%$ looking at the objects exhibited. However, with respect to previous sections, it is the interactive screen which proved to be the most popular informative tool.

As far as the information panel is concerned, it comprises two texts (together with their English translation), of nearly 30 lines each. The first text entitled "La Stereoscopia" attracted the attention of participants the most. In particular, dividing the text into three main areas of interest (two halves of the first column and the entire second column), the first part obtained 58\% of the total time, the second $29 \%$, and $11 \%$ for the third. The text does not describe the objects in the showcases but provides visitors with details and information on stereoscopy in general. The only 
reference to an object displayed in the showcase, and specifically the stereoscope, can be found in the first half of our area of interest, which obtained the highest percentage of fixations $(58 \%)$.

Once again, no fixation was detected for its English translation. Despite that, the reference to a non-Italian figure, the Scottish inventor "David Brewster", attracted the attention of readers considerably, registering a higher number of fixations, as shown in the heat map ${ }^{5}$ of Figure 2 below:

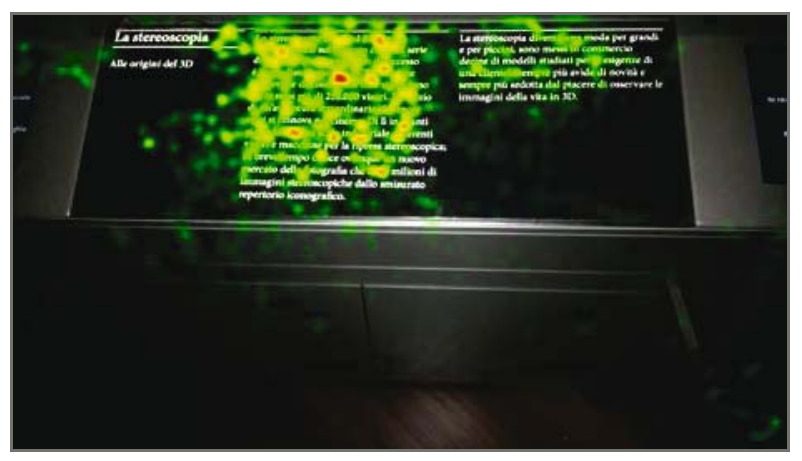

Figure 2 "Stereoscopy": Heat map

The same pattern, as well as the average reading behaviour, was detected in the following area, called "Panorama". More generally, 13.3\% of participants ignored the area under scrutiny, and the average visit duration was one minute and three seconds. Therefore, it ranks fourth together with the "Peepshows" section in terms of number of visitors, and again fourth in terms of time spent visiting it.

Even in this section, $92 \%$ of the total time was devoted to the informative area, only leaving less than $8 \%$ for the objects exhibited in the showcase. Once again, the information panel comprises two different two-column texts, of nearly 30 lines each, and fixations again concentrated at the beginning of the first columns of each text.

In particular, after analysing the heat maps, we detected a higher concentration of fixations at the beginning of column one of the first text, and precisely in correspondence to the French expression "La nature à coup d'œil" (nature at a glance), left untranslated for Italian audiences. A similar behaviour was found in column three, where the gaze mostly focused on the French word "Daguerre" (referring to French artist and photographer Louis Daguerre), and the English expression "Portable Diorama". Being both foreign expressions to the Italian reader, they required more cognitive effort and thus longer fixations. The same mechanism was replicated in column four, containing the foreign and very technical expression "Polyorama Panoptique", 
referring to a device based on Daguerre's Diorama.

\section{Conclusions}

Museums, heritage organizations and cultural spaces in general have transformed from objectbased collections to people-based institutions (Komarac, 2014). Therefore, they are changing to ensure that all people, including (but not exclusively) those with disabilities can enjoy the same experiences, thus being accessible to all (see Section 2).

Despite this, for many museums, access still means physical access, thus failing to embrace a more heterogeneous concept of accessibility, which combines inclusion and universality (see Section 2). Even if museums have made progress in the past decades in terms of accessibility, there is still room for improvement.

The analysis carried out on our European sample shows that museums still rely heavily on paper resources to provide access services to their visitors (print guides/brochures/leaflets and information panels/posters) and that the implementation of new technologies was listed as the top priority for providing future access services.

As for paper materials, these are formats which cannot be printed or downloaded for people to adapt them according to their needs, such as changing the font size or converting them using textto-speech software. Print or downloadable versions of documents and informative materials are not only essential for people with visual, learning, cognitive or physical disabilities (such as coordination problems, among others), but also to foreign visitors who can select the appropriate language to access the information provided.

As far as language is concerned, visitors may be unfamiliar with the specific terminology used in a given field of expertise. Our study at Turin's Museo Nazionale del Cinema also demonstrated that the length, the layout, the use of special language and the number of technical terms may have a negative impact on the way visitors experience the museum. The eye-tracking study showed that reading was neither linear nor focused, with fixations mainly concentrated on the beginning of each section of the informative texts, and at foreign and technical-specific terms.

The time spent reading depended on the duration of fixations, which in turn increased with the increased cognitive effort demanded by the decoding of the words. Furthermore, as shown in Section 4, foreign and technical terms in the Italian texts required more cognitive effort (therefore longer fixations). This, in addition to the absence of a "pyramidal" structure in which the 
information is placed in a hierarchal order, did not offer a clear reading path to visitors, thus leading visitors to spend much more time on reading than on observing the objects exhibited.

Therefore, simplifying the text, breaking texts down into logical chunks or using bullet points may have a positive impact on museum visits, enabling visitors to dedicate their time on the exhibition rather than on decoding complex texts. This would make not only the informative elements but also the whole visiting experience more widely enjoyable and accessible.

As a consequence, accessibility may contribute to both attracting and building long-term relationships with a wide range of audiences, thus reflecting the expectations of an ongoing political, social, environmental and economic context and responding to the needs of the wider community.

\section{Endnotes}

${ }^{1}$ https://en.unesco.org/themes/museums (Accessed 15 October 2017).

${ }^{2}$ The FACS project was coordinated by Elena Di Giovanni, and the complete list of all research team members is available on the official FACS website (http://blog.unimc.it/facs/partners/). I am deeply grateful to Elena Di Giovanni, principal researcher, and to all team members who actively participated in the studies presented in Section 3 and 4 of the present paper, although I acknowledge sole responsibility for any mistakes. I am also grateful to Tomaso Vido and Lorena Del Vino from SR Labs (http://www.srlabs.it) for their support and helpful feedback during and after our experiment at Museo Nazionale del Cinema (Turin, Italy).

3 The total time each participant has fixated on each area/object of interest, expressed in HH:MM:SS:mmm.

4 The total time each participant has fixated on each area/object of interest, expressed in HH:MM:SS:mmm. The average fixation duration is normally $200-250$ milliseconds.

${ }^{5}$ It shows how looking is distributed over the stimulus, using different colours to illustrate the number of fixations or for how long (duration) they fixated within that area. Red usually indicates the highest number of fixations or the longest time, and green the least, with varying levels in between.

\section{References}

AA.VV. 2015. Conference Proceedings: The Future of Education: 5th Conference. Padova: Libreria Universitaria.

Álvarez de Morales Mercado, C. and Jiménez Hurtado, C. 2016. Patrimonio Cultural Para Todos: Investigación Aplicada en Traducción Accesible. Lachar, Granada: Tragacanto.

Ang, I. 2005. The Predicament of Diversity: Multiculturalism in Practice at the Art Museum. London Sage.

Davidson, B., Heald, C.L. and Hein, G.E. 1991. "Increased Exhibit Accessibility Through Multisensory Interaction." In Curator: The Museum Journal, vol. 34, no. 4, pp. 273-290.

De Lauretis, T. 1987. Technologies of Gender: Essays on Theory, Film and Fiction. Bloomington: Indiana University Press.

Díaz Cintas, J. 2005. "Audiovisual Translation Today - A Question of Accessibility for All.” In Translating Today vol 4, pp. 3-5.

Díaz Cintas, J., Orero P., and Remael, A. 2007. "Media For All: A Global Challenge.” In: Díaz Cintas, J., P. Orero and A. Remael (eds.) Media for All: Subtitling for the Deaf, Audio 
Description, and Sign Language. Amsterdam: Rodopi, pp. 11-20.

Dizionario della Lingua Italiana De Mauro Online. 2017. Available at:

$<$ https://dizionario.internazionale.it $>$. [Accessed 15 October 2017]

EGMUS (2012). Museum Statistics. Available at:

http://www.egmus.eu/nc/en/statistics/complete_data/z/0/. [Accessed 15 October 2017].

Falk, J.H. 2016. Identity and The Museum Visitor Experience. London: Routledge.

Greco, G.M. 2016. "On Accessibility as a Human Right, with an Application to Media Accessibility." In: Matamala, A. and P. Orero (eds.). Researching Audio Description New Approaches. Palgrave Macmillan: London, pp. 11-33.

Holmqvist, K., Nyström M., Andersson R., Dewurst R., Jarodzka H., Van de Weijer J. 2015. Eye tracking: A Comprehensive Guide to Methods and Measures. Oxford: Oxford University Press.

Jiménez Hurtado, C., Seibel, C., Soler Gallego, S. and Herrero Díaz, S. 2012. Museums for All: Translation and Interpreting for Multimodal Spaces As a Tool for Universal Accessibility. Universitat d'Alacant. Available at: <http://hdl.handle.net/10045/26955>. [Accessed 15 October 2017].

Kawashima, N., 1999. "Knowing the Public: A Review of Museum Marketing Literature and Research.” In Museum Management and Curatorship, vol. 17, no. 1, pp. 21-39.

Komarac, T. 2014. "A New World for Museum Marketing? Facing the Old Dilemmas While Challenging New Market Opportunities.” In Market-Tržište, vol. 26, no. 2, pp. 199-214.

Limesurvey GmbH. 2003. Limesurvey: An Open Source Survey Tool. Hamburg, Germany: LimeSurvey GmbH. Available at: <http://www.limesurvey.org>.

Mangiron, C., Orero, P. and O'Hagan, M. 2014. Videogame Localisation and Accessibility: Fun for All. Bern: Peter Lang.

Mokatren M. and Kuflik, T. 2016. "Exploring the Potential Contribution of Mobile Eye-Tracking Technology in Enhancing the Museum Visit Experience." In CEUR Workshop Proceedings, pp. 23-31.

Nuovo Vocabolario Base della Lingua Italiana De Mauro Online. 2016. Available at: $<$ https://www.internazionale.it/opinione/tullio-de-mauro/2016/12/23/il-nuovo-vocabolario-dibase-della-lingua-italiana $>$. [Accessed 15 October 2017]

Rocque, S., Langevin, J., Chalghoumi, H., Gorayeb, A. 2015. "Universal Accessibility." In Conference Proceedings - The Future of Education: 5th Conference, Florence, 8-9 June 2017. Padova: Libreria Universitaria, pp. 175-179.

Ruiz, B., Pajares, J.L., Utray, F. and Moreno, L. 2011. "Design for All in Multimedia Guides for Museums." In Computers in Human Behavior, vol. 27, no. 4, pp. 1408-1415.

Ryhl, C. 2009. "Architecture for Senses." In: Vavik, T. (ed.). Inclusive Buildings, Products \& Services: Challenges in Universal Design. Trondheim, Norway: Tapir Academic Press, pp. 10427.

Ryhl, C. 2016. "So Much More Than Building Regulations: Universal Design and the Case of Practice." In: Sørmoen, O., A. Arenghi and I. Garofolo (eds.). Accessibility As a Key Enabling Knowledge for Enhancement of Cultural Heritage. Milano: Franco Angeli, pp. 115-130.

Sørmoen, O., Arenghi, A. and Garofolo, I. 2016. Accessibility As a Key Enabling Knowledge for Enhancement of Cultural Heritage. Milano: Franco Angeli.

Steinfeld, E. and Maisel, J.L. 2014. Universal Design: Creating Inclusive Environments. Johanneshov: MTM.

UN General Assembly. 2007. Convention on the Rights of Persons with Disabilities: Resolution / adopted by the General Assembly, 24 January 2007, A/RES/61/106. Available at: http://www.refworld.org/docid/45f973632.html. [Accessed 15 October 2017]. 
Francesca Raffi

University of Macerata

Via Crescinbeni, 30/32, Macerata, Italy

francesca.raffi@unimc.it 